\title{
Effect of arginine or glutamine supplementation and milk feeding allowance on small intestine development in calves
}

\author{
P. van Keulen, ${ }^{1,2}$ M. A. Khan, ${ }^{1} \oplus$ J. Dijkstra, ${ }^{2} \odot$ F. Knol, ${ }^{1}$ and S. A. McCoard ${ }^{1 *}$ (৫) \\ ${ }^{1}$ Animal Nutrition and Physiology Team, AgResearch Grasslands Ltd., Palmerston North 4474, New Zealand \\ ${ }^{2}$ Animal Nutrition Group, Wageningen University and Research, $6700 \mathrm{AH}$ Wageningen, the Netherlands
}

\begin{abstract}
The development of the small intestine (SI) is important for the health and growth of neonatal calves. This study evaluated the effect of arginine (Arg) and glutamine (Gln) supplementation and 2 levels of milk allowance on the histomorphological development of the SI in preweaning calves. Sixty mixed-sex Friesian $\times$ Jersey calves $(3-5 \mathrm{~d}$ of age) were offered reconstituted whole milk (125 g/L, 26\% fat, $26 \%$ protein) at either high (20\% of arrival body weight/d; HM) or low ( $10 \%$ of arrival body weight/d; LM) milk allowance without (Ctrl) or with supplementary Arg or Gln (at $1 \%$ of milk dry matter) in a $2 \times 3$ factorial design (n $=10 /$ treatment). After $35 \mathrm{~d}$ on the diets, all calves were slaughtered to collect tissues for examination of SI development. Calves in the HM group had higher milk intake, total weight gain, and average daily gain compared with LM calves, but no effect of AA supplementation nor an interaction between milk allowance and AA supplementation was observed. For the duodenum, we observed an AA by milk allowance interaction for villus height and width, and goblet cell number per villus (HM-Arg > HM-Gln > HM-Ctrl), and villus height to crypt depth ratio (HM-Arg > HM-Gln $=$ HM-Ctrl), but no effect of AA supplementation in the LM group. Goblet cell numbers per $100 \mu \mathrm{m}$ of SI were greater in Arg-supplemented calves than in unsupplemented controls, with Gln-supplemented calves intermediate to but not different from the other groups. Epithelium thickness was greater in LM than in HM calves. Villus density, crypt depth, and muscle thickness did not differ between groups. For the jejunum, there was an AA by milk allowance interaction for villus height, villus surface area, and villus height to crypt depth ratio (HM-Arg = HM-Gln > HM-Ctrl), with no effect of AA supplementation in the LM groups. Amino
\end{abstract}

Received August 31, 2019.

Accepted January 24, 2020.

*Corresponding author: sue.mccoard@agresearch.co.nz acid supplementation affected goblet cell number per villus (HM-Gln > HM-Ctrl calves, HM-Arg intermediate), and both LM-Arg and LM-Gln calves had greater numbers than LM-Ctrl calves. Villus width, crypt depth, and muscle thickness were greater in HM than LM calves but there was no effect of AA supplementation. Villus density, goblet cell number per $100 \mu \mathrm{m}$ of SI, and epithelium thickness were unaffected by AA supplementation and milk allowance. Milk allowance and AA supplementation had no effect on SI morphology in the ileum. Increasing milk allowance improved villus height, width, and surface area but only in Argor Gln-supplemented calves, not in control calves. The observed changes in development may be important for intestinal functionality, integrity, and barrier function in preweaning calves, potentially through increased cell growth and proliferation or reduced levels of cellular atrophy.

Key words: L-arginine, L-glutamine, milk allowance, small intestine development

\section{INTRODUCTION}

Small intestine (SI) development in the neonatal calf is crucial for feed digestion, nutrient absorption, and protection against external pathogens (Blum, 2006). Structural and functional changes of the SI influence neonatal intestinal health and growth performance (Hammon and Blum, 1997). Compared with rumen development, the SI has received little attention in calf nutrition (Steele et al., 2016).

Amino acids are a major fuel for rapidly dividing intestinal enterocytes and play a key role in the development and function of the SI (Wu, 2009). Arginine (Arg) and Glutamine (Gln) are conditionally essential AA for the growth of neonates ( $\mathrm{Wu}, 2009)$. In addition to the role that Arg plays as a building block for protein synthesis, it is a common substrate for nitric oxide and polyamine synthesis and is a key signal regulating intestinal cell proliferation (Tan et al., 2010). The SI is dependent on Gln because it is used by enterocytes as a source of energy as well as for the endogenous synthesis 
of Arg (Wu and Knabe, 1995). In piglets, supplementation of Arg increases the intestinal absorptive area (Wang et al., 2012), and dietary Gln supplementation improves intestinal morphology in weaning piglets (Jiang et al., 2009) and reduces the severity of diarrhea and intestinal villus atrophy in weaned pigs (Wu et al., 1996). Glutamine supplementation has also been shown to improve intestinal morphology (villus height and crypt depth) in weaned calves (Hu et al., 2013). The effect of Gln and Arg on SI development in preweaning calves has received little attention.

Increasing preweaning growth through provision of higher milk allowance can have lifetime effects on the age at first insemination and milk production in dairy cows (Davis Rincker et al., 2011; Soberon et al., 2012). Thus, there is an increasing trend globally to offer calves higher milk allowances. Increasing milk allowance increases calf growth but suppresses solid feed intake before weaning and therefore delays rumen development (Khan et al., 2007, 2016). The effect of increased milk intake on SI development in calves is largely unknown (Khan et al., 2011; Steele et al., 2016).

This study was designed to evaluate the effect of low versus high milk allowance (whole milk powder) with or without Arg or Gln supplementation fed at $1 \%$ of whole milk powder DM on SI development in calves in the first 5 wk of life.

\section{MATERIALS AND METHODS}

All animal manipulations including animal feeding, management, health, welfare, and sampling were reviewed and approved (AE13831) by the Animal Ethics Committee of AgResearch Grasslands, Palmerston North, New Zealand.

\section{Experimental Design, Animals, and Diets}

Sixty mixed-sex Friesian $\times$ Jersey calves $(4 \pm 1 \mathrm{~d}$ of age) were sourced from 2 commercial farms, transported to a dedicated rearing facility ( $<2 \mathrm{~h}$ transport), and randomly allocated to 1 of 6 treatments in a $2 \times$ 3 factorial design ( $\mathrm{n}=10$ /treatment) balanced for sex (30 females and 30 males), arrival BW $(29.3 \pm 3.8 \mathrm{~kg})$, and farm source. The number of animals per treatment was determined using a power analysis to detect a $25 \%$ difference in duodenal villus height where the mean was $291 \mu \mathrm{m}$ and SD 40 (data from $\mathrm{Hu}$ et al., 2013) at 80\% power and a significance level of $P<0.05 ; 5$ animals per group were required. To detect similar treatment differences in jejunal and ileal villus height using data from the same source to estimate population variance, 3 to 4 animals per treatment group were required, whereas similar differences in crypt depth would require 5 to 9 animals per group. Power analysis calculations were undertaken using a 2-sample t-test using the statistical program R, software version 3.4.2 (R Core Team, 2017; https://www.R-project.org/). The trial was undertaken in April and May 2016. Calves were housed in sawdustbedded group pens $(3.5 \times 9.0 \mathrm{~m})$ with 20 animals per pen (10 with a high milk allowance and 10 with a low milk allowance), with one milk and meal feeding stall per pen. The bedding surface area of each pen was sprayed weekly with disinfectant (Virkon; DuPont, Auckland, New Zealand) with calves remaining in the pens during direct application of the disinfectant to the bedding. Calves were individually fed reconstituted whole milk powder (WMP; NZAgbiz, Hamilton, New Zealand; Table 1) mixed at $125 \mathrm{~g} / \mathrm{L}$ at 35 to $37^{\circ} \mathrm{C}$ in warm water using an automatic feeding system (CalfSmart, Palmerston North, New Zealand). Calves were offered a low milk (LM; $10 \%$ of arrival $\mathrm{BW} / \mathrm{d}$ ) or high milk (HM; $20 \%$ of arrival BW/d) allowance without (control, Ctrl) or with supplementary L-Arg or L-Gln (both Merck Ltd., Auckland, New Zealand) included at 1\% of the WMP DM throughout the 5-wk rearing period (i.e., no change to the feed allowance was made). This approach created 6 treatment comparisons: HM-Arg, LM-Arg, HM-Gln, LM-Gln, HM-Ctrl, and LM-Ctrl. The Arg and Gln were formulated into a saline solution ( $\mathrm{pH}$ 7.0) prepared daily and provided in the milk via a liquid medicine doser integrated into the automatic feeding units. For consistency, the milk offered to the control groups was fortified with a saline solution at an equivalent volume to the treatment diets. Milk and supplement allowance were controlled for individual calves using the automatic feeders and electronic ear tags. The calves had free access to $50 \%$ of their daily allowance during the first $12 \mathrm{~h}$ and the remaining $50 \%$ of their daily allowance during the remaining $12 \mathrm{~h}$ of each day. The automatic milk feeding system and medicine doser were calibrated weekly to confirm the individual allocations of milk and supplementary Arg and Gln. Milk and supplement (Arg/Gln) intake were recorded automatically at each feeding and used to calculate daily intakes. Individual calves were observed daily for the presence of any signs of sickness or scours (fecal score of $\geq 2$ as described in scouring score by School of Veterinary Medicine, University of Wisconsin, Madison) to document the incidence of diarrhea.

Calves in the HM allowance groups were initially fed $10 \%$ of their arrival BW per day, which was gradually increased to $20 \% / \mathrm{d}$ by d 7 of the trial to minimize the risk of nutritional scours. A grain-based concentrate (SealesWinslow, Morrinsville, New Zealand; Table 1) and water were offered ad libitum throughout the trial. 
Samples of WMP and calf starter were collected weekly, pooled, and analyzed in triplicate for the following nutritional components (AOAC International, 2016): DM (method 945.15), ash (method 942.05), CP (method 992.15), crude fat (method 932.02), starch (method 920.40), NDF (method 2002.04), and ADF (method 973.18) by a commercial laboratory (Hill Laboratories Ltd., Hamilton, New Zealand). Calf starter samples were subjected to in vitro OM digestibility (OMD) testing and digestibility of OM in DM (DOMD) was calculated from OMD using Australian Fodder Industry Association Standard equation (AFIA, 2009). The ME content of starter feed was calculated using the equation $\mathrm{ME}=\mathrm{DOMD} \% \times 0.16(\mathrm{AFRC}, 1993)$. The ME content of WMP was calculated based on NRC (2001) equations: Gross energy $(\mathrm{Mcal} / \mathrm{kg})=0.057 \times$ $\mathrm{CP} \%+0.092 \times$ fat $+0.0395 \times$ lactose $\%$ and $\mathrm{ME}$ (Mcal $/ \mathrm{kg})$.

\section{Tissue Sampling and Processing}

At the end of the trial ( $35 \pm 1 \mathrm{~d}$ of age), all calves were euthanized by captive bolt stunning and exsanguinated. The visceral organs were removed immediately and the eviscerated carcass weight, including hide, hoofs, head, and tail, was recorded. The entire SI starting from the pyloric sphincter to the ileocecal valve was removed from the gastrointestinal tract. Tissue samples were collected from the duodenum $(10 \mathrm{~cm}$ posterior to the pylorus), jejunum (30 $\mathrm{cm}$ posterior to the mesenteric junction), and ileum (10 $\mathrm{cm}$ anterior to the ileocecal junction).

Table 1. Nutritional composition of the experimental feeds (on a DM basis except for DM \%)

\begin{tabular}{lcc}
\hline & \multicolumn{2}{c}{ Experimental feed ${ }^{1}$} \\
\cline { 2 - 3 } Item, \% of DM & WMP & CS \\
\hline DM (\% of wet weight) & 95.4 & 87.6 \\
CP & 25.6 & 21.5 \\
Crude fat & 25.8 & 2.3 \\
Ash & 6.0 & 6.3 \\
Lactose $^{2}$ & 42.6 & \\
NFC & & 58.9 \\
Starch & & 42.4 \\
NDF & & 11.0 \\
ADF & 5.1 & 6.3 \\
ME $^{4}$ (Mcal/kg DM) & 5.2 \\
\hline IWP
\end{tabular}

${ }^{1} \mathrm{WMP}=$ whole milk powder; $\mathrm{CS}=$ calf starter (pelleted).

${ }^{2}$ Lactose $=100-\mathrm{CP}-$ crude fat - ash.

${ }^{3} \mathrm{NFC}=100-\mathrm{CP}-$ crude fat - ash $-\mathrm{NDF}$.

${ }^{4}$ The ME content of starter feed was calculated according to AFRC (1993) equation and in WMP according to the equations given in NRC (2001).
The tissue samples were immediately flushed with ice-cold saline to remove luminal contents and fixed in $10 \%$ buffered formalin for later histological analysis of intestinal morphology. Histology slices were prepared by a commercial histopathology laboratory (Massey University, Palmerston North, New Zealand). Two sections per animal were trimmed from each sample doing a transversal cut through the villi and dehydrated overnight through graded alcohols $(70 \%, 95 \%$, and absolute alcohol) at ambient temperature. Samples were cleared in xylene and impregnated with Histosec paraffin pastilles (Merck Ltd., Auckland, New Zealand) under pressure at $60^{\circ} \mathrm{C}$ in a tissue processor (Excelsior ES, ThermoFisher, Albany, New Zealand). Treated tissues were embedded (HistoStar, ThermoFisher, Albany, New Zealand) and cut with a rotary microtome (microTec, Walldorf, Germany). The $4-\mu \mathrm{m}$-thick sections were stained using hematoxylin-eosin by means of an autostainer (Leica Biosystems, Wetzlar, Germany).

\section{Morphological Analysis}

Morphometric analysis included evaluation of villus height and width, crypt depth, villus height to crypt depth (VH:CD) ratio, villus density, goblet cell number (both per villus and per linear $100 \mu \mathrm{m}$ of epithelium), muscle layer, and epithelium thickness (Figure 1). Measurements were taken from 2 sections per animal and a minimum of 10 villi per section (i.e., minimum of 20 villi per animal). In addition, villus area was calculated according to Kisielinski et al. (2002). Ten measurements of each variable from each of the 2 sections were taken using a light microscope (BH2, Olympus, Tokyo, Japan) coupled with a digital camera (ProgRes C14, Jenoptik, Jena, Germany) to a computer with image processing software (Image-Pro 7.0, Media Cybernetics, Rockville, MD). Histological analysis was performed by an investigator blinded to treatment allocation of the calves.

\section{Statistical Analysis}

All measurement variables were analyzed with linear mixed modeling using the statistical program R, software version 3.4.2 (R Core Team, 2017; https://www .R-project.org/). Factors included in the model were AA supplementation (Arg or Gln), milk level (low or high), and their interaction, with calf considered the experimental unit for all variables. Calf sex, farm, and pen were included as categorical random effects, and age was considered a continuous random effect. Two calves in the LM-Gln group died during the experiment because of a navel infection that failed to respond to 
treatment, and one calf (HM-Arg group) had recurring pneumonia. These 3 calves were excluded from the analyses.

Normality of distribution was checked by means of normality plots of the standardized residuals and Shapiro-Wilk test for normality, in which a $P$-value $\leq 0.05$ was considered not normally distributed. As a result, VH:CD ratio was transformed using a logarithmic scale. Multiple comparisons were performed by means of Tukey's adjustment. Probability values $\leq 0.05$ were considered significantly different. Data are presented as predicted means and their average standard error (SE) unless otherwise noted.

\section{RESULTS}

Total milk DMI in the first $28 \mathrm{~d}$ of the trial was greater in HM calves than LM calves $(15.1 \pm 0.15$ vs. $8.4 \pm 0.16 \mathrm{~kg} ; P<0.001 ; 16 \%$ and $9 \%$ of $\mathrm{BW}$, respectively) and was not influenced by AA supplementation $(P=0.632)$; there was no milk allowance $\times$ supplementation interaction $(P=0.481)$. The average supplementary Arg and Gln intakes (mean $\pm \mathrm{SD}$ ) in addition to Arg and Gln provided in the WMP were $3.3 \pm 0.42 \mathrm{~g} / \mathrm{d}$ (LM-Arg), $3.2 \pm 0.53 \mathrm{~g} / \mathrm{d}$ (LM-Gln), 5.5 $\pm 0.79 \mathrm{~g} / \mathrm{d}$ (HM-Arg), and $5.7 \pm 0.52 \mathrm{~g} / \mathrm{d}$ (HM-Gln). Total live weight gain from wk 1 to 4 was greater in HM than LM calves $(12.8 \pm 0.92$ vs. $5.6 \pm 1.18 \mathrm{~kg}, P$ $<0.001$ ), but was not affected by AA supplementation $($ Arg, $8.9 \pm 1.05$, Gln, $8.8 \pm 1.19$, Ctrl, $9.7 \pm 1.08 \mathrm{~kg}$, $P=0.830)$, and no AA supplementation $\times$ milk allowance interaction was observed $(P=0.926)$. Overall ADG was greater in HM than LM calves $(440 \pm 32.4$ vs. $190 \pm 41.2 \mathrm{~g} / \mathrm{d}, P<0.001)$ but was not affected by AA supplementation (Arg, $310 \pm 37.0$, Gln, $302 \pm 42.0$, Ctrl, $335 \pm 38.2, P=0.804)$, and no AA supplementation $\times$ milk feeding level interaction was observed $(P=0.959)$. Calves were generally healthy during the trial and required few medical interventions, with a low incidence of diarrhea ( 5 of 57 calves with diarrhea present for $\geq 6$ out of $30 \mathrm{~d}$ ) and no differences evident between treatment groups $(P>0.10)$. Two calves died as a result of scours that did not respond to treatment (LM-Gln). One calf had a navel abscess (LM-Ctrl) and another had a navel infection (LM-Gln), both responded well to antibiotic and anti-inflammatory treatment. One calf had labored breathing and a high temperature (HM-Arg), which resolved quickly following antibiotic and anti-inflammatory treatment and remained in the trial. No other health issues were observed.

Light microscope photos of sections of the duodenum, jejunum, and ileum of the SI are presented in Figure 1.

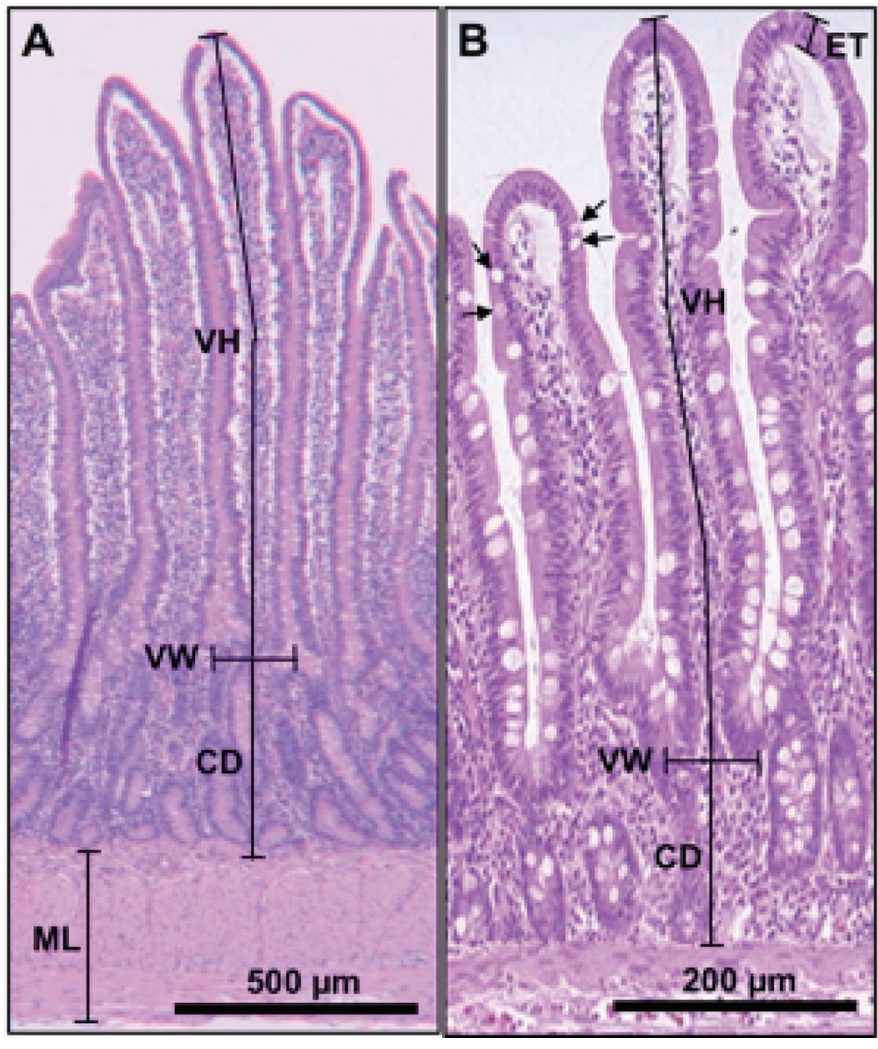

Figure 1. Representative histological pictures of the small intestine of milk-fed calves, magnified $40 \times(\mathrm{A})$ or $100 \times(\mathrm{B})$. Villus height $(\mathrm{VH})$ measurement started from the villus-crypt transition to the apex of the villus; crypt depth (CD) was measured from the villus-crypt transition to its base, the muscularis mucosae. The width of the villus (VW) was measured at the basal region of the villus, which coincides with the top of the crypt. In addition, mucus-holding goblet cells (black arrows), muscle layer (ML), and epithelium thickness (ET) were measured.

The effect of Arg and Gln supplementation, milk feeding level, and their interaction on histomorphological development in the duodenum, jejunum, and ileum are shown in Table 2.

\section{Duodenum}

We observed an AA supplementation $\times$ milk feeding level interaction for villus height, villus width, surface area (Figure 2), and goblet cell number per villus (Figure 3); each of these parameters was increased in HM-Arg calves relative to HM-Ctrl and HM-Gln calves, with HM-Gln having increased values compared with HM-Ctrl; no effects of AA supplementation were observed in the LM group. An AA supplementation $\times$ milk feeding level interaction was evident for $\mathrm{VH}: \mathrm{CD}$ ratio, whereby HM-Arg calves had a greater $\mathrm{VH}$ :CD ratio than HM-Gln and HM-Ctrl calves, with no effect of 
AA supplementation observed in the LM groups (Table 3). Goblet cell numbers per $100 \mu \mathrm{m}$ of SI were greater in Arg-supplemented calves relative to unsupplemented controls, with Gln-supplemented calves intermediate but not different from the other groups. We observed no effect of milk feeding levels nor a supplement $\times$ milk feeding level interaction (Figure 3). Epithelium thickness was greater in LM than in HM calves but no effect of AA supplementation nor an interaction between AA supplementation and milk feeding level was evident (Table 2). Villus density, crypt depth, and muscle thickness did not differ between treatment groups (Table 2).

\section{Jejunum}

We observed an AA supplementation $\times$ milk feeding level interaction for villus height, villus surface area (Figure 4), and VH:CD ratio (Table 3), whereby HM-Arg and HM-Gln calves had greater villus height, surface area, and VH:CD ratio than HM-Ctrl calves, whereas no effects were observed in the LM groups. Supplementation with AA affected goblet cell number per villus, whereby HM-Gln calves had greater numbers than HM-Ctrl calves, with HM-Arg calves intermediate, and both LM-Arg and LM-Gln calves had greater numbers than LM-Ctrl calves (Figure 2). Villus width, crypt depth, and muscle thickness were greater in HM than LM calves but there was no effect of AA supplementation or no AA $\times$ milk feeding level interaction (Table 2). Villus density, goblet cell number per 100 $\mu \mathrm{m}$ of SI, and epithelium thickness were unaffected by AA supplementation and milk feeding level (Table 2).

\section{Ileum}

No effects of AA supplementation, milk feeding level, or their interaction were observed in the ileum (Table 2, Table 3, Figure 2, and Figure 4).

\section{DISCUSSION}

During the first few weeks of life, considerable physical and physiological development of the gastrointestinal tract occurs, which enables calves to transition from milk to solid feed (Baldwin et al., 2004; Khan et al., 2016). The development of the gastrointestinal tract, and more specifically the SI, consists of 3 aspects (Santaolalla et al., 2011; Jeurissen et al., 2002): innate immunity (IgA secretion and Paneth cell antimicrobial function), functionality (ability to digest and absorb nutrients), and integrity (capacity to protect against microbial toxins and microorganisms entering from the lumen into the body). These functions are intricately linked because integrity influences absorption of nutrients, and nutrient absorption is required for differentiation and development of intestinal cells to maintain integrity, as shown in pigs (Pluske et al., 1997), calves (Seegraber and Morrill, 1982), and poultry (Jeurissen et al., 2002).

Villus growth is an important parameter in increasing intestinal nutrient absorption and, therefore, important to support calf growth (Seegraber and Morrill, 1982; Hammon and Blum, 1997). The increased villus height, width, VH:CD ratio (an indicator of enhanced intestinal cell proliferation or reduced cell apoptosis; observed in

Table 2. Histomorphology of the small intestine (duodenum, jejunum, and ileum) in 35-d-old calves offered a low or high milk allowance (10\% vs. $20 \%$ of arrival-BW/d) supplemented with L-arginine (Arg) or L-glutamine (Gln) at $1.0 \%$ of milk DM or no supplement (Ctrl) ${ }^{1}$

\begin{tabular}{|c|c|c|c|c|c|c|c|c|c|c|}
\hline Item & \multicolumn{3}{|c|}{ Low milk allowance } & \multicolumn{3}{|c|}{ High milk allowance } & $\mathrm{SE}$ & \multicolumn{3}{|c|}{$P$-value ${ }^{2}$} \\
\hline \multicolumn{11}{|l|}{ Duodenum } \\
\hline Villus density (no./mm) & 8.8 & 9.2 & 9.5 & 9.1 & 9.1 & 9.9 & 0.32 & 0.065 & 0.524 & 0.794 \\
\hline Muscle thickness $(\mu \mathrm{m})$ & 1,154 & 1,165 & 1,146 & 1,171 & 1,122 & 1,177 & 66.5 & 0.633 & 0.641 & 0.780 \\
\hline Epithelium thickness $(\mu \mathrm{m})$ & 39.6 & 39.3 & 38.0 & 35.9 & 36.6 & 36.0 & 1.26 & 0.310 & 0.046 & 0.495 \\
\hline Villus density (no./mm) & 7.1 & 6.9 & 6.9 & 6.9 & 6.6 & 7.1 & 0.24 & 0.479 & 0.667 & 0.638 \\
\hline Muscle thickness $(\mu \mathrm{m})$ & 446 & 474 & 490 & 478 & 537 & 528 & 21.8 & 0.079 & 0.003 & 0.300 \\
\hline Epithelium thickness $(\mu \mathrm{m})$ & 29.7 & 30.4 & 32.1 & 29.3 & 32.3 & 29.3 & 1.18 & 0.181 & 0.293 & 0.178 \\
\hline \multicolumn{11}{|l|}{ Ileum } \\
\hline Crypt depth $(\mu \mathrm{m})$ & 504 & 478 & 498 & 513 & 500 & 535 & 18.5 & 0.259 & 0.141 & 0.759 \\
\hline Villus density (no./mm) & 7.5 & 7.5 & 7.7 & 7.7 & 7.1 & 7.0 & 0.34 & 0.600 & 0.245 & 0.388 \\
\hline Muscle thickness $(\mu \mathrm{m})$ & 652 & 647 & 652 & 649 & 681 & 642 & 42.8 & 0.615 & 0.258 & 0.494 \\
\hline
\end{tabular}

${ }^{1}$ Data are presented as predicted means and standard error (SE).

${ }^{2}$ The effect of supplementation $(\mathrm{S})$, milk allowance $(\mathrm{M})$, and their interaction $(\mathrm{S} \times \mathrm{M})$ are presented. 
this study only in calves supplemented with $1 \% \mathrm{Arg}$ ), and villus area in the duodenum and jejunum of calves fed a high milk allowance supplemented with $1 \%$ Arg or $1 \%$ Gln indicate greater villus growth. These results are consistent with the positive effects on villus development reported in intrauterine growth restricted and normal birth weight neonatal piglets following dietary Arg-supplemented (0.6\% of milk DM; Wang et al., 2012;

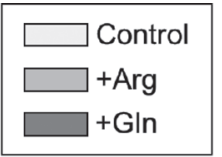

\section{Duodenum}
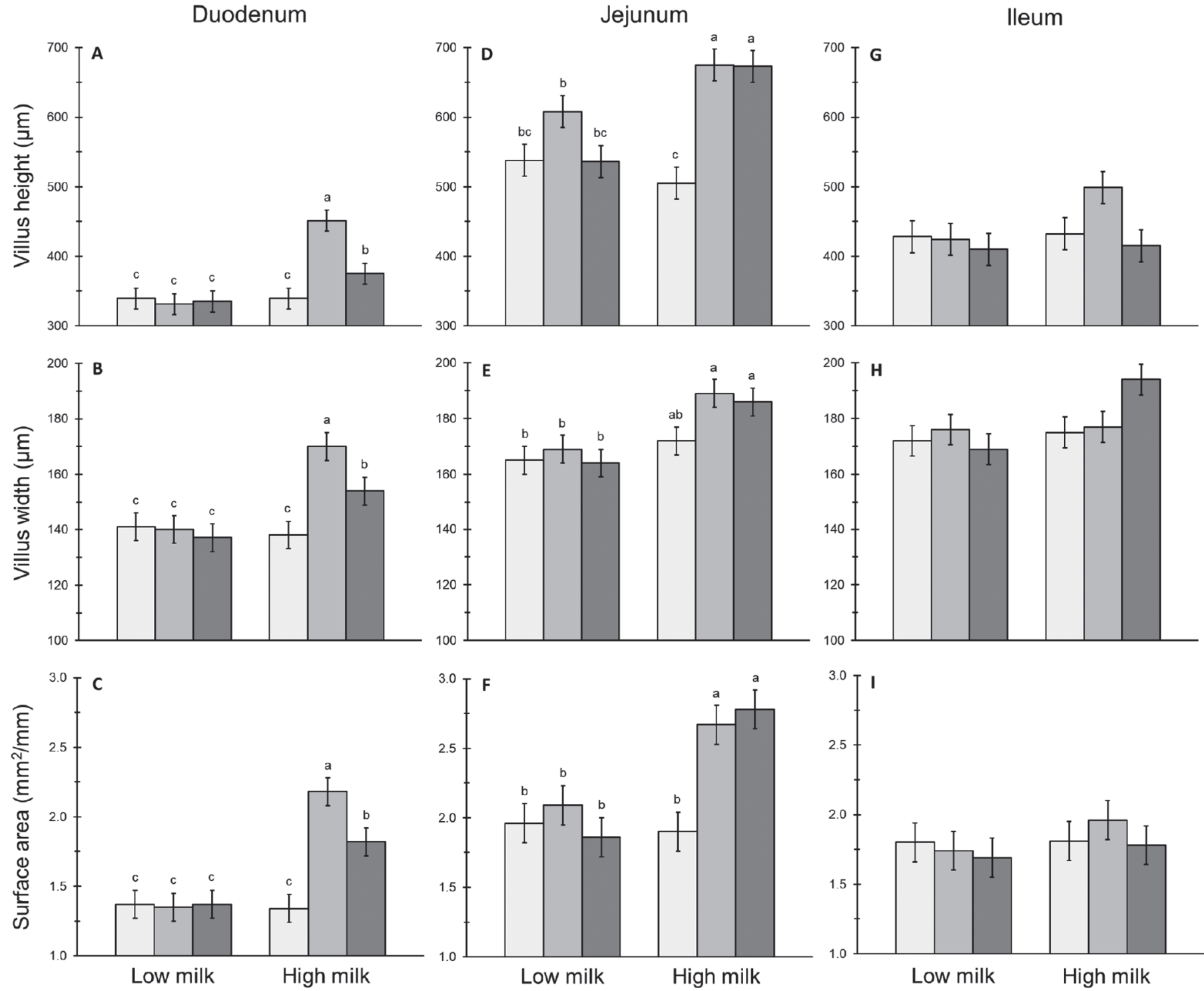

Figure 2. Small intestinal histomorphology (villus height, width, and surface area) for the duodenum (A-C), jejunum (D-F), and ileum $(\mathrm{G}-\mathrm{I})$ of 35-d-old calves fed an unsupplemented control diet or supplemented with arginine (+Arg) or glutamine (+Gln; both at $1 \%$ of milk DM) in combination with a low milk level ( $10 \%$ of arrival weight) or a high milk level (20\% of arrival weight). Bars with different letters (a-c) show differences within milk level (Tukey; $P \leq 0.05)$. Villus area $\left(\mu \mathrm{m}^{2} \times 10^{3}\right)$ was calculated according to Kisielinski et al. (2002). Predicted means and their average standard error (SEM) are presented. A milk allowance $\times$ supplement interaction was present for villus height $(P<$ $0.001)$, villus width $(P=0.005)$, and villus area $(P<0.001)$ in the duodenum and for villus height $(P=0.026)$ and villus area $(P=0.025)$ in the jejunum. A milk allowance effect was present for villus width in the jejunum $(P=0.033)$ but no other effects of Arg or Gln supplementation, milk allowance, or their interaction were observed $(P>0.05)$. 
Table 3. Villus height to crypt depth ratio in the small intestine (duodenum, jejunum, and ileum) in 35-d-old calves offered a low or high milk allowance $\left(10 \%\right.$ vs. $20 \%$ of arrival-BW/d) supplemented with L-arginine (Arg) or L-glutamine (Gln) at $1.0 \%$ of milk DM or no supplement (Ctrl) ${ }^{1}$

\begin{tabular}{|c|c|c|c|c|c|c|c|c|c|}
\hline \multirow[b]{2}{*}{ Item } & \multicolumn{3}{|c|}{ Low milk allowance } & \multicolumn{3}{|c|}{ High milk allowance } & \multicolumn{3}{|c|}{$P$-value ${ }^{2}$} \\
\hline & Ctrl & Arg & Gln & Ctrl & Arg & Gln & $\mathrm{S}$ & M & $\mathrm{S} \times \mathrm{M}$ \\
\hline Duodenum & $\begin{array}{l}0.95^{\mathrm{b}} \\
(0.78,1.07)\end{array}$ & $\begin{array}{l}0.97^{\mathrm{b}} \\
(0.79 .1 .10)\end{array}$ & $\begin{array}{l}1.10^{\mathrm{b}} \\
(0.88,126)\end{array}$ & $\begin{array}{l}0.96^{\mathrm{b}} \\
(0.78,1.09)\end{array}$ & $\begin{array}{l}1.27^{\mathrm{a}} \\
(1.04 .1 .43)\end{array}$ & $\begin{array}{l}0.93^{\mathrm{b}} \\
(0.77 .1 .04)\end{array}$ & 0.154 & 0.713 & 0.022 \\
\hline Jejunum & $\begin{array}{l}1.30^{\mathrm{ab}} \\
(1.11,1.43)\end{array}$ & $\begin{array}{l}1.44^{\mathrm{a}} \\
(1.205,1.60)\end{array}$ & $\begin{array}{l}1.27^{\mathrm{ab}} \\
(1.05,1.42)\end{array}$ & $\begin{array}{l}1.05^{\mathrm{b}} \\
(0.88,1.17)\end{array}$ & $\begin{array}{l}1.43^{\mathrm{a}} \\
(1.21,1.59)\end{array}$ & $\begin{array}{l}1.43^{\mathrm{a}} \\
(1.23,1.57)\end{array}$ & 0.017 & 0.526 & 0.034 \\
\hline Ileum & $\begin{array}{l}0.94 \\
(0.85,1.03)\end{array}$ & $\begin{array}{l}0.92 \\
(0.78,1.02)\end{array}$ & $\begin{array}{l}0.91 \\
(0.76,1.01)\end{array}$ & $\begin{array}{l}0.97 \\
(0.81,1.08)\end{array}$ & $\begin{array}{l}1.09 \\
(0.93,1.20)\end{array}$ & $\begin{array}{l}0.90 \\
(0.78,0.99)\end{array}$ & 0.289 & 0.297 & 0.341 \\
\hline
\end{tabular}

${ }^{\mathrm{a}, \mathrm{b}}$ Values within a row with different superscripts differ significantly $(P \leq 0.05)$.

${ }^{1}$ Data are presented as back-transformed means and 95\% confidence intervals.

${ }^{2}$ The effect of supplementation $(\mathrm{S})$, milk allowance $(\mathrm{M})$, and their interaction $(\mathrm{S} \times \mathrm{M})$ are presented.

Xu et al., 2012), dietary Gln-supplemented (1\% of milk DM) weaned piglets (Wu et al., 1996), and parenterally Gln-supplemented preweaning NaCl-challenged calves
(Zhou et al., 2012; Hu et al., 2013). However, the interaction between Arg or Gln supplementation and milk feeding level is intriguing. At the low milk allowance,

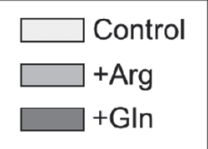

Duodenum
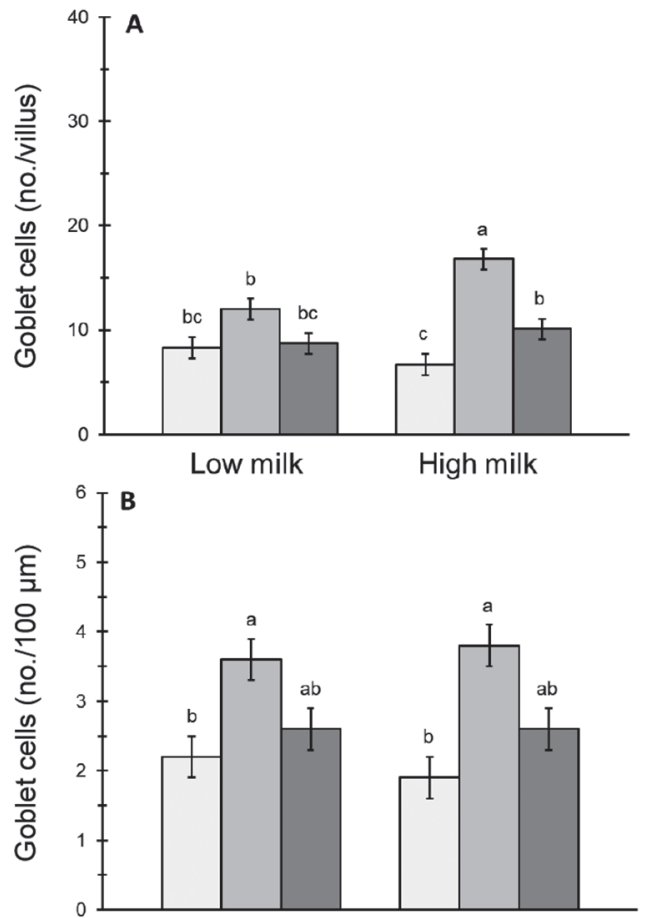

Low milk

High milk

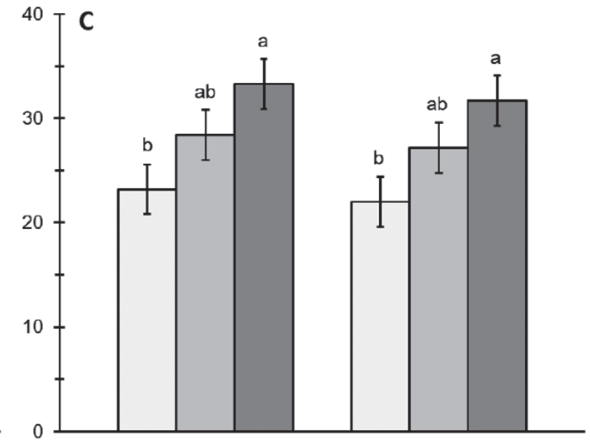

High milk

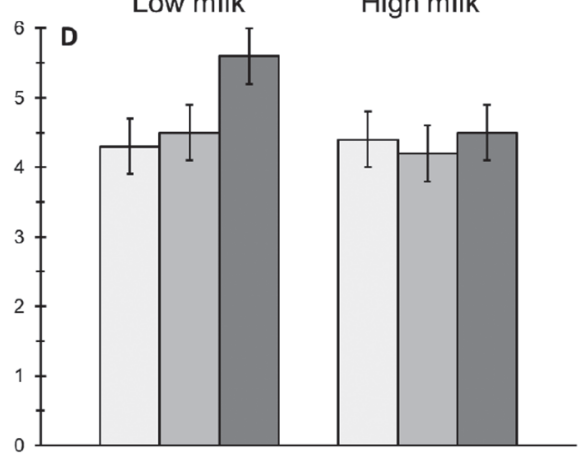

Low milk

High milk
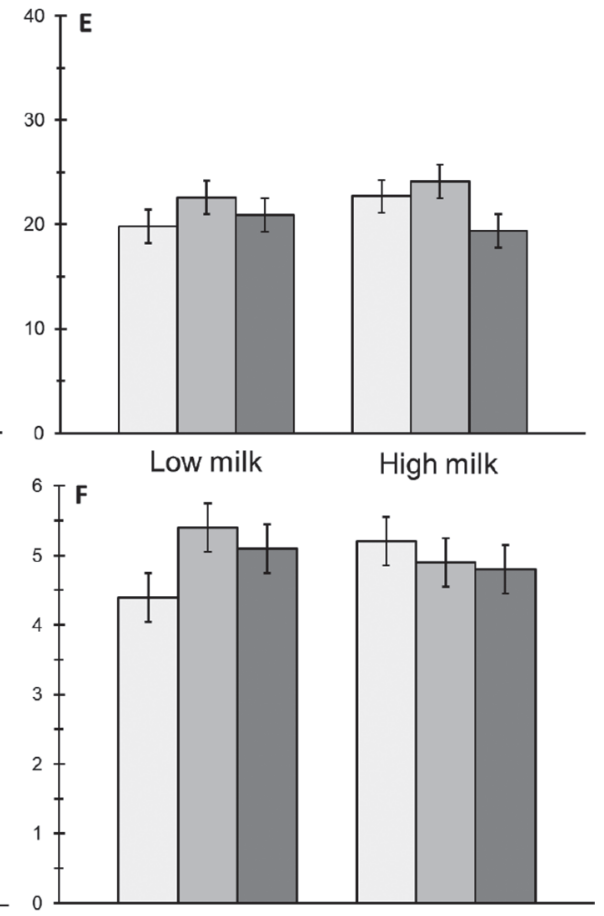

Low milk

High milk

Figure 3. Goblet cell count (per villus and per 100- $\mu$ m linear section of small intestine) for the duodenum (A and B), jejunum (C and D), and ileum (E and F) of 35-d-old calves fed an unsupplemented control diet or supplemented with arginine (+Arg) or glutamine (+Gln; both at $1 \%$ of milk DM) in combination with a low milk level (10\% of arrival weight) or a high milk level (20\% of arrival weight). Bars with different letters $(\mathrm{a}-\mathrm{c})$ show differences within milk level (Tukey; $P \leq 0.05)$. Predicted means and their average standard error (SEM) are presented. A milk allowance $\times$ supplement interaction was present for goblet cell number per villus in the duodenum $(P<0.001)$. Amino acid supplementation affected goblet cell number per $100 \mu \mathrm{m}$ of small intestine in the duodenum $(P=0.003)$ and goblet cell number per villus in the jejunum $(P$ $=0.004)$. No other effects of Arg or Gln supplementation, milk allowance, or their interaction were observed $(P>0.05)$. 
Arg and Gln supplementation did not influence villus growth, indicating a nutrient or factor other than Arg or Gln to enhance SI development is lacking or that the absolute amount of supplementary Arg and Gln did not reach the threshold to induce further villus growth. The lack of effect of Gln supplementation on villus growth at low milk allowance is consistent with the inability of $1 \%$ Gln fortification of milk replacer fed at 10 to $12 \%$ of BW (similar to the LM group in the present study) to minimize the negative effects of replacing milk protein in milk replacer with soy protein on villus growth in the SI during the preweaning period in calves (Drackley et al., 2006). In our study, increasing milk allowance to supply more energy and nutrients during the first 5 wk of age had some effect on villus development in the jejunum but not in the duodenum and ileum in the absence of Arg and Gln. These findings highlight the synergy between AA supplementation and milk allowance to promote SI development in calves. Therefore, we suggest that enhanced villus development can be achieved with Arg and Gln supplementation but only when the supply of milk is increased. Alternatively, dose-response effects of AA have been reported in both piglet and rodent studies (Rhoads and Wu, 2009); therefore, it is possible that the total amount of supplementary Arg or Gln provided in the milk was insufficient to elicit an effect on SI development of calves fed the lower milk allowance. The experimental design in the current study was used to evaluate the effect of a practical approach to deliver enhanced Arg and Gln supply via the milk (supplementation of AA at $1 \% \mathrm{DM}$ of WMP). This level of supplementation is equivalent to $\sim 30 \%$ and $\sim 3 \%$ increase in supply of free Arg and Gln, respectively, in milk, while the supply and ratio of all other AA remained constant. Further studies are required to determine whether the effects observed in the current study were the result of enhanced Arg or Gln supply per se (i.e., $\sim 3 \mathrm{~g} / \mathrm{d}$ in the LM group and

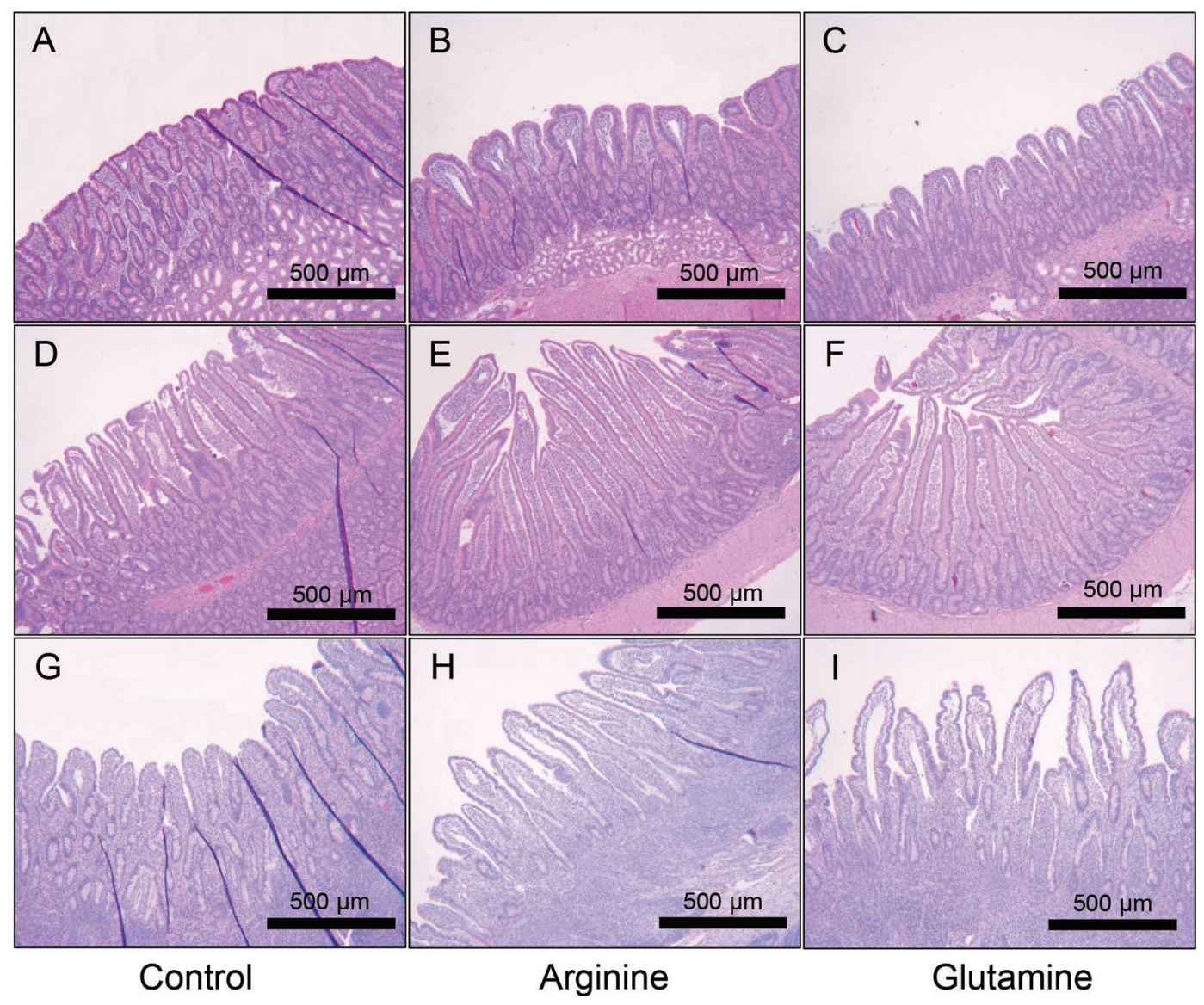

Figure 4. Light micrographs (hematoxylin and eosin-stained, $4-\mu \mathrm{m}$ sections, $40 \times$ magnification, black bar represents $500 \mu \mathrm{m})$ of the duodenum $(\mathrm{A}-\mathrm{C})$, jejunum $(\mathrm{D}-\mathrm{F})$, and ileum $(\mathrm{G}-\mathrm{I})$ of 35-d-old calves fed an unsupplemented control diet or supplemented with arginine (+Arg) or glutamine (+Gln; both at $1 \%$ of milk DM) in combination with a low milk level (10\% of arrival weight; low milk, not shown) or a high milk level ( $20 \%$ of arrival weight; high milk). 
$\sim 6 \mathrm{~g} / \mathrm{d}$ in the HM group) or were due to the potential requirement for greater basal milk allowance to enable an animal to respond when Arg and Gln supply is enhanced in a dose-responsive manner. Furthermore, the combined effect of Arg and Gln supplementation on SI development warrants further investigation.

Goblet cells are intestinal mucin-secreting cells that create a physical barrier at the mucosal surfaces of the intestine, which serve as the front line of innate host defense by binding with bacteria, viruses, and parasites (Kim and Ho, 2010). Therefore, a greater number of goblet cells indicates greater integrity of the intestinal mucosa. Despite the importance of mucus to gastrointestinal function, relatively little is known about its characteristics and factors affecting goblet cells in preruminants (Steele et al., 2016). Like other intestinal epithelial cells (Tan et al., 2010) and vascular endothelial cells (Zhan et al., 2008), goblet cells may depend on Arg, Gln, and their metabolites for proliferation and differentiation (Rhoads and Wu, 2009). As observed for villus growth, Arg and Gln supplementation influenced goblet cell numbers but not in a consistent way. Although goblet cell numbers per villus were increased with Arg and Gln supplementation in the duodenum in the HM group only, Arg and Gln supplementation increased goblet cell numbers per villus in the jejunum in both groups. In contrast, only Arg supplementation increased goblet cell numbers per unit of linear measurement of duodenum but not per unit of linear measurement of jejunum in both HM and LM groups, with no other effects of AA supplementation, milk feeding level, or their interaction in the duodenum and jejunum, and with no effect of AA or milk feeding level on goblets cells in the ileum. In pigs, Arg (Wu et al., 2010) and Gln supplementation (Jiang et al., 2009) increased goblet cell number throughout the small intestine, which contrasts with the results of the current study, suggesting potential species-specific or dose-response effects. Collectively, these results indicate a potential effect of Arg and Gln supplementation on mucus production in the duodenum and jejunum; however, further validation studies are required, including those that directly test gut barrier function.

The mechanisms that mediate the effects of Arg and Gln supplementation and milk allowance on morphological development of the small intestine remain to be established. Both Arg and Gln are conditionally essential AA for the growth of neonates (Wu et al., 2009). They individually activate signaling pathways in the intestinal epithelium to promote protein synthesis and potentially inhibit protein degradation, enhance mucosal cell migration and restitution, and promote epithelial cell proliferation (Rhoads and Wu, 2009). Arginine also plays an important role in cellular homeostasis and survival in the intestine through nitric oxide-dependent cyclic GMP signaling-induced physiological events (Rhoads and $\mathrm{Wu}, 2009$ ). The SI is dependent on Gln because it is used by enterocytes as a source of energy as well as for the endogenous synthesis of Arg (Wu and Knabe, 1995). The results of the current study suggest that Arg, Gln, and their products might have a local signaling effect in SI enterocytes and goblet cells of the intestinal villi, which was previously shown in pigs (Flynn and Wu, 1996) and more recently in rats (Xiao et al., 2016) and lambs (Zhang et al., 2018). The mammalian target of rapamycin (mTOR) pathway has been implicated in the control of intestinal epithelial cell renewal (Yang et al., 2016) and glucose homeostasis in the small intestine (Waise et al., 2019). Whether increased mTOR signaling, nitric oxide, or polyamines mediated the positive effects on the development of the bovine SI warrants further investigation; interestingly, our results do indicate more pronounced effects on several aspects of duodenal development (villus height, width, and area, VH:CD ratio, and goblet cells per villus) at the HM level for Arg than for Gln supplementation.

\section{CONCLUSIONS}

Overall, our key finding was that Arg and Gln supplementation of WMP (1\% DM basis) can enhance intestinal development and integrity in the duodenum and jejunum (but not ileum), either through increased cell growth or proliferation or through reduced levels of cellular atrophy, but only when calves were fed the higher milk allowance. Inconsistent effects of Arg and Gln supplementation on goblet cell numbers in the duodenum and jejunum may indicate potential effects on intestinal integrity, but this remains to be validated. Milk consumption without Arg or Gln supplementation had little or no effect on duodenum and ileum physical development and only minor effects on jejunum physical development. Whether the interaction between AA supplementation and milk feeding level is caused by a dose-response effect (i.e., insufficient amount of Arg or Gln to promote SI development in the LM calves) or whether the basal supply of milk can influence the animal's response to supplementary Arg or Gln remains to be established.

\section{ACKNOWLEDGMENTS}

The authors thank AgResearch's Strategic Science Investment Fund for the financial support. We gratefully acknowledge the technical expertise of AgResearch staff members Sarah Maclean, Adrian Molenaar, Jason 
Peters, Gregory Skelton, and Annemiek Welboren (intern student) for their assistance with the animal trial and tissue collection, and Catherine Lloyd-West for assistance with the statistical analyses. The authors have not stated any conflicts of interest.

\section{REFERENCES}

AFIA. 2009. Laboratory Methods Manual-A Reference Manual of Standard Methods for the Analysis of Fodder. Australian Fodder Industry Association (AFIA) Limited, Melbourne, VIC, Australia.

AFRC. 1993. Energy and Protein Requirements of Ruminants. An advisory manual prepared by the AFRC technical committee on responses to nutrients. CAB International, Wallingford, UK.

AOAC International. 2016. Official Methods of Analysis. 20th ed. AOAC International, Gaithersburg, MA.

Baldwin, R. L., K. R. McLeod, J. L. Klotz, and R. N. Heitmann. 2004. Rumen development, intestinal growth and hepatic metabolism in the pre- and postweaning ruminant. J. Dairy Sci. 87(E. Suppl.):E55-E65. https://doi.org/10.3168/jds.S0022 $-0302(04) 70061-2$.

Blum, J. W. 2006. Nutritional physiology of neonatal calves. J. Anim. Physiol. Anim. Nutr. (Berl.) 90:1-11. https://doi.org/10.1111/j .1439-0396.2005.00614.x.

Davis Rincker, L. E., M. J. VandeHaar, C. A. Wolf, J. S. Liesman, L. T. Chapin, and M. S. Weber Nielsen. 2011. Effects of intensified feeding of heifer calves on growth, pubertal age, calving age, milk yield, and economics. J. Dairy Sci. 94:3554-3567. https://doi.org/ $10.3168 /$ jds.2010-3923.

Drackley, J. K., R. M. Blome, K. S. Bartlett, and K. L. Bailey. 2006. Supplementation of $1 \%$ L-glutamine to milk replacer does not overcome the growth depression in calves caused by soy protein concentrate. J. Dairy Sci. 89:1688-1693. https://doi.org/10.3168/ jds.S0022-0302(06)72236-6.

Flynn, N. E., and G. Wu. 1996. An important role for endogenous synthesis of arginine in maintaining arginine homeostasis in neonatal pigs. Am. J. Physiol. 271:R1149-1155. https://doi.org/10.1152/ ajpregu.1996.271.5.R1149.

Hammon, H., and J. W. Blum. 1997. Prolonged colostrum feeding enhances xylose absorption in neonatal calves. J. Anim. Sci. 75:29152919. https://doi.org/10.2527/1997.75112915x.

Hu, Z. Y., H. W. Su, S. L. Li, and Z. J. Cao. 2013. Effects of parenteral administration of glutamine on autophagy of liver cell and immune responses in weaned calves. J. Anim. Physiol. Anim. Nutr. (Berl.) 97:1007-1014. https://doi.org/10.1111/jpn.12002.

Jeurissen, S. H. M., F. Lewis, J. D. van der Klis, Z. Mroz, J. M. J. Rebel, and A. A. H. M. Huurne. 2002. Parameters and techniques to determine intestinal health of poultry as constituted by immunity, integrity, and functionality. Curr. Issues Intest. Microbiol. $3: 1-14$.

Jiang, Z. Y., L. H. Sun, Y. C. Lin, X. Y. Ma, C. T. Zheng, G. Zhou, F. Chen, and S. T. Zou. 2009. Effects of dietary glycyl-glutamine on growth performance, small intestinal integrity, and immune responses of weaning piglets challenged with lipopolysaccharide. J. Anim. Sci. 87:4050-4056. https://doi.org/10.2527/jas.2008-1120.

Khan, M. A., A. Bach, D. M. Weary, and M. A. G. von Keyserlingk. 2016. Invited review: Transitioning from milk to solid feed in dairy heifers. J. Dairy Sci. 99:885-902. https://doi.org/10.3168/jds.2015 -9975 .

Khan, M. A., H. J. Lee, W. S. Lee, H. S. Kim, K. S. Ki, T. Y. Hur, G. H. Suh, S. J. Kang, and Y. J. Choi. 2007. Structural growth, rumen development, and metabolic immune responses of Holstein male calves fed milk through step-down and conventional methods. J. Dairy Sci. 90:3376-3387. https://doi.org/10.3168/jds.2007 -0104 .

Khan, M. A., D. M. Weary, and M. A. G. von Keyserlingk. 2011. Invited review: Effects of milk ration on solid feed intake, wean- ing, and performance in dairy heifers. J. Dairy Sci. 94:1071-1081. https://doi.org/10.3168/jds.2010-3733.

Kim, Y. S., and S. B. Ho. 2010. Intestinal goblet cells and mucins in health and disease: Recent insights and progress. Curr. Gastroenterol. Rep. 12:319-330. https://doi.org/10.1007/s11894-010-0131 -2 .

Kisielinski, K., S. Willis, A. Prescher, B. Klosterhalfen, and V. Schumpelick. 2002. A simple new method to calculate small intestine absorptive surface in the rat. Clin. Exp. Med. 2:131-135. https://doi.org/10.1007/s102380200018.

NRC. 2001. Nutrient Requirements of Dairy Cattle. 7th ed. National Academies Press, Washington, DC.

Pluske, J., D. J. Hampson, and I. H. Williams. 1997. Factors influencing the structure and function of the small intestine in the weaned pig: A review. Livest. Prod. Sci. 51:215-236. https://doi.org/10 .1016/S0301-6226(97)00057-2.

R Core Team. 2017. R: A language and environment for statistical computing. R Foundation for Statistical Computing, Vienna, Austria. http: //www.R-project.org/.

Rhoads, J. M., and G. Wu. 2009. Glutamine, arginine, and leucine signaling in the intestine. Amino Acids 37:111-122. https://doi.org/ 10.1007/s00726-008-0225-4.

Santaolalla, R., M. Fukata, and M. T. Abreu. 2011. Innate immunity in the small intestine. Curr. Opin. Gastroenterol. 27:125-131. https://doi.org/10.1097/MOG.0b013e3283438dea.

Seegraber, F. J., and J. L. Morrill. 1982. Effect of soy protein on calves' intestinal absorptive ability and morphology determined by scanning electron microscopy. J. Dairy Sci. 65:1962-1970. https:// doi.org/10.3168/jds.S0022-0302(82)82445-4.

Soberon, F., E. Raffrenato, R. W. Everett, and M. E. Van Amburgh. 2012. Preweaning milk replacer intake and effects on long-term productivity of dairy calves. J. Dairy Sci. 95:783-793. https://doi .org $/ 10.3168 / j d s .2011-4391$.

Steele, M. A., G. B. Penner, F. Chaucheyras-Durand, and L. L. Guan. 2016. Development and physiology of the rumen and the lower gut: Targets for improving gut health. J. Dairy Sci. 99:4955-4966. https://doi.org/10.3168/jds.2015-10351.

Tan, B., Y. Yin, X. Kong, P. Li, X. Li, H. Gao, X. Li, R. Huang, and G. Wu. 2010. L-Arginine stimulates proliferation and prevents endotoxin-induced death of intestinal cells. Amino Acids 38:12271235. https://doi.org/10.1007/s00726-009-0334-8.

Waise, T. M. Z., M. Rasti, F. A. Duca, S.-Y. Zhang, P. V. Bauer, C. J. Rhodes, and T. K. T. Lam. 2019. Inhibition of upper small intestinal mTOR lowers plasma glucose levels by inhibiting glucose production. Nat. Commun. 10:714. https://doi.org/10.1038/ s41467-019-08582-7.

Wang, Y., L. Zhang, G. Zhou, Z. Liao, H. Ahmad, W. Liu, and T. Wang. 2012. Dietary L-arginine supplementation improves the intestinal development through increasing mucosal Akt and mammalian target of rapamycin signals in intra-uterine growth retarded piglets. Br. J. Nutr. 108:1371-1381. https://doi.org/10.1017/ S0007114511006763.

Wu, G. 2009. Amino acids: Metabolism, functions, and nutrition. Amino Acids 37:1-17. https://doi.org/10.1007/s00726-009-0269-0.

Wu, G., F. W. Bazer, T. A. Davis, S. W. Kim, P. Li, J. M. Rhoads, M. C. Satterfield, S. B. Smith, T. E. Spencer, and Y. Yin. 2009. Arginine metabolism and nutrition in growth, health and disease. Amino Acids 37:153-168. https://doi.org/10.1007/s00726-008-0210-y.

Wu, G., and D. A. Knabe. 1995. Arginine synthesis in enterocytes of neonatal pigs. Am. J. Physiol. 269:R621-629. https://doi.org/10 .1152/ajpregu.1995.269.3.R621.

Wu, G., S. A. Meier, and D. A. Knabe. 1996. Dietary glutamine supplementation prevents jejunal atrophy in weaned pigs. J. Nutr. 126:2578-2584. https://doi.org/10.1093/jn/126.10.2578.

Wu, X., Z. Ruan, Y. Gao, Y. Yin, X. Zhou, L. Wang, M. Geng, Y. Hou, and G. Wu. 2010. Dietary supplementation with L-arginine or N-carbamylglutamate enhances intestinal growth and heat shock protein-70 expression in weanling pigs fed a corn and soybean meal-based diet. Amino Acids 39:831-839. https://doi.org/ 10.1007/s00726-010-0538-y. 
Xiao, L., W. Cao, G. Liu, T. Fang, X. Wu, G. Jia, X. Chen, H. Zhao, J. Wang, C. Wu, and J. Cai. 2016. Arginine, N-carbamylglutamate, and glutamine exert protective effects against oxidative stress in rat intestine. Anim. Nutr. 2:242-248. https://doi.org/10.1016/j aninu.2016.04.005

Xu, Q., Z. Jiang, Y. Lin, C. Zheng, and S. Wang. 2012. Effects of dietary supplementation with combined arginine and glutamine on growth performance and small intestinal development in neonatal pigs. J. Anim. Vet. Adv. 11:3187-3193. https://doi.org/10.3923/ javaa.2012.3187.3193

Yang, H., X. Xiong, X. Wang, and Y. Yin. 2016. Mammalian target of rapamycin signaling pathway changes with intestinal epithelial cells renewal along crypt-villus axis. Cell. Physiol. Biochem. 39:751-759. https://doi.org/10.1159/000445665.

Zhan, Z., S. Kim, W. Liu, and J. Wang. 2008. Dietary arginine supplementation affects microvascular development in the small intestine of early-weaned pigs. J. Nutr. 138:1304-1309.

Zhang, H., F. Zhao, A. Peng, L. Dong, M. Wang, L. Yu, J. J. Loor, and H. Wang. 2018. Effects of dietary L-arginine and $N$-carbamyl- glutamate supplementation on intestinal integrity, immune function, and oxidative status in intrauterine-growth-retarded suckling lambs. J. Agric. Food Chem. 66:4145-4154. https://doi.org/10 .1021 /acs.jafc.8b00726.

Zhou, Y., P. Zhang, G. Deng, X. Liu, and D. Lu. 2012. Improvements of immune status, intestinal integrity and gain performance in the early-weaned calves parenterally supplemented with L-alanyl-Lglutamine dipeptide. Vet. Immunol. Immunopathol. 145:134-142. https://doi.org/10.1016/j.vetimm.2011.10.020.

\section{ORCIDS}

M. A. Khan (ํ) https://orcid.org/0000-0001-7590-5128

J. Dijkstra @ https://orcid.org/0000-0003-3728-6885

S. A. McCoard $\odot$ https://orcid.org/0000-0002-4806-0323 